\title{
Operational Risk Assessment of Distribution Network Equipment Based on Rough Set and D-S Evidence Theory
}

\author{
Cunbin Li, ${ }^{1}$ Gefu Qing, ${ }^{1,2}$ Peng Li, ${ }^{1}$ and Tingting Yin ${ }^{1}$ \\ ${ }^{1}$ School of Economics and Management, North China Electric Power University, Beijing 102206, China \\ ${ }^{2}$ State Grid East Inner Mongolia Electric Power Co., Ltd., Hohhot Power Supply Bureau, Hohhot 010050, China \\ Correspondence should be addressed to Tingting Yin; yintt1989@yeah.net
}

Received 29 August 2013; Revised 22 November 2013; Accepted 22 November 2013

Academic Editor: Antonio J. M. Ferreira

Copyright (c) 2013 Cunbin Li et al. This is an open access article distributed under the Creative Commons Attribution License, which permits unrestricted use, distribution, and reproduction in any medium, provided the original work is properly cited.

\begin{abstract}
With the increasing complication, compaction, and automation of distribution network equipment, a small failure will cause an outbreak chain reaction and lead to operational risk in the power distribution system, even in the whole power system. Therefore, scientific assessment of power distribution equipment operation risk is significant to the security of power distribution system. In order to get the satisfactory assessment conclusions from the complete and incomplete information and improve the assessment level, an operational risk assessment model of distribution network equipment based on rough set and D-S evidence theory was built. In this model, the rough set theory was used to simplify and optimize the operation risk assessment indexes of distribution network equipment and the evidence D-S theory was adopted to combine the optimal indexes. At last, the equipment operational risk level was obtained from the basic probability distribution decision. Taking the transformer as an example, this paper compared the assessment result obtained from the method proposed in this paper with that from the ordinary Rogers ratio method and discussed the application of the proposed method. It proved that the method proposed in this paper is feasible, efficient, and provides a new way to assess the distribution network equipment operational risk.
\end{abstract}

\section{Introduction}

As the basis part of the power system, the distribution network has direct contact with the power user. The task of distribution network is to assign the electrical energy to users, and the safe and stable operation of the distribution network equipment is closely related to the reliability of power supply. The construction of smart grid leads to a wider application of new distribution network equipment such as transformers, SF6 circuit breakers, vacuum circuit breakers, and box-type substations. With the increasing complication, compaction, and automation of distribution network equipment, a small fault somewhere in the equipment may outbreak chain reaction, causing catastrophic damages to the distribution network system, even in the entire power system, namely, operational risk $[1,2]$. Therefore, the operational risk assessment of distribution network equipment is a very important topic with high theoretical and practical significance.

In the basic theory of equipment risk assessment, a variety of mathematical methods such as risk matrix method, Monte
Carlo method [3], failure mode and impact analysis [4], and fault tree analysis [5] are used to describe the uncertainty and adverse consequences of various risk events. The most widely-used methods in equipment asset management are risk matrix method and Monte Carlo method. With further study of equipment risk assessment, new methods like AHP and information fusion algorithm have been introduced. Yang deeply analyzed the special equipment risk evaluation system and used the Analytic Hierarchy Process (AHP) to build a hierarchical mathematical model for the special equipment risk assessment [6]. Based on the thought of information fusion technology, and combined with the reality of fault diagnosis, Yang developed a neural network evidence fusion fault diagnosis system [7]. For the problem that the single assessment method cannot make full use of the various operational information of the secondary equipment in $750 \mathrm{kV}$ grid, Wang proposed a state assessment method for secondary equipment in $750 \mathrm{kV}$ grid based on information fusion technology [8]. The methods above lay a solid theoretical foundation for the study and practice 
of distribution network equipment risk assessment. As one of the main equipment in the distribution network, the research of transformer's risk has attracted much attention. Xiao adopted the BP neural network and genetic algorithm to study the optimization method of index weights calculation in the risk assessment of transformer, which provided more accurate evidence for transformer risk management [9]. As traditional risk assessment methods have shortcomings such as that the evaluation indexes are treated equally, the assessment cannot be taken when the Risk Priority Number (RPN) is equal, and the assessment result's accuracy is relative, Feng built a cloud model including the indexes of occurrence, severity, and detectability and employed it to get the maintenance decision of the transformer's components [10]. For real-time and objective measurement of in-service transformer failure risks, Yu proposed a transformer risk assessment method based on fuzzy AHP and artificial neural network [11]. Based on Borda Number Theory, Wang put forward a fuzzy comprehensive risk assessment model of power transformer [12].

In summary, most studies on equipment risk apply the risk assessment theory to construct evaluation index system and carried out corresponding assessment, and transformer works were the main object to study the distribution network equipment. Though these studies have solved the problem of equipment risk assessment to some extent, there are still some problems for further study. For example, there are multiple indexes to describe the operational risk of a distribution network device, but they play different roles in the operational risk assessment. It is a critical issue to exclude the indexes that are irrelevant or unimportant from the risk assessment index system and get the accurate risk state of the equipment. So, applying the attribute reduction function of rough set and D-S evidence theory, this paper proposed an operational risk assessment model of distribution network equipment based on rough set and D-S evidence theory to further study the operational risk management of distribution network equipment. The rest of the paper is arranged as follows. Part two introduced the rough set theory and D-S evidence theory firstly and built an operational risk assessment model of distribution network equipment. Taking the transformer as an instance, part three makes a detailed description of equipment operational risk assessment methods based on rough set and D-S evidence theory and carries out an example to discuss the assessment results and their application. Part four gives the conclusion of this paper.

\section{Operational Risk Assessment Model of Distribution Network Equipment}

2.1. Rough Set Theory. As a theory of data analysis and processing, rough set theory was founded by Polish scientist Z. Pawlak in 1982. It is a theoretical method to study the representation, learning, and induction of incomplete and uncertain knowledge and data [13] and has been widely studied and applied to the classification and knowledge acquisition of imprecise, uncertain, and incomplete information. The main purpose of rough set is to make use of knowledge reduction to get the decision or classification rules of the problem with the classification capacity unchanged. Currently, the rough set theory has been widely used in the field of information science, medicine, chemistry, machinery, and management science [14-17] and has become an important tool for knowledge discovery. Knowledge reduction is one of the core contents in rough set theory. The knowledge (attributes) in the knowledge base is not equal, and even some of the knowledge is redundant. Knowledge reduction is to delete irrelevant or unimportant knowledge redundancy to simplify judgment rules with the classification capacity of knowledge base unchanged.

The discernibility matrix proposed by a Polish mathematician, A. Skowron, is one of the efficient algorithms for information system reduction, and it can calculate the reduction easily [18].

Definition 1. Let $S=(U, A, V, f)$ be a decision table, where $A=C \cup D, C \cap D=\varnothing, C$ is a condition attribute set, and $D$ is a decision attribute set. If $a(x)$ is the value of record $x$ on attribute $a$, namely, $a(x)=f(x, a)$ and $C_{i j}$ is the element of discernibility matrix, then the discernibility matrix is defined as

$$
C_{i j}= \begin{cases}\left\{a \in C, a\left(x_{i}\right) \neq a\left(x_{j}\right)\right\}, & D\left(x_{i}\right) \neq D\left(x_{j}\right) \\ \varnothing, & D\left(x_{i}\right)=D\left(x_{j}\right) .\end{cases}
$$

If $C_{i j}=\left\{a_{1}, a_{2}, \ldots, a_{k}\right\} \neq \varnothing$, then specify a Boolean function $a_{1} \vee a_{2} \vee \cdots a_{k}$ and use $\sum C_{i j}$ to represent it; if $C_{i j}=\varnothing$, then let the Boolean constant be 1 . The discernibility function $\Delta$ is defined as

$$
\Delta=\prod \sum C_{i j}
$$

All the conjunctive expressions in the minimal disjunctive form of function $\Delta$ are the reduction of attribute set A. That means that the reduction is minimal attribute subset that can distinguish all the objects.

2.2. D-S Evidence Theory. D-S evidence theory is a powerful tool to deal with uncertain problems brought by cognition limitations. D-S evidence theory was formally founded by Shafer in 1976 [18]. In recent years, D-S evidence theory has drawn increasing attention and made some achievements in theory. Uncertain information from different sources such as multiple sensors or experts should be considered comprehensively to solve problems in the fields such as medical diagnosis, target recognition, and military $[19,20]$. In addition, D-S evidence theory has been successfully applied in fault diagnosis, condition monitoring, information fusion, pattern recognition, intelligent decision-making, and other fields [21].

(1) The Composition of Two Belief Functions. Let $\mathrm{Bel}_{1}, \mathrm{Bel}_{2}$ be two belief functions in the same recognition framework, $m_{1}, m_{2}$ be the corresponding basic probability assignments, 
and the focal elements are $A_{1}, \ldots, A_{K}$ and $B_{1}, \ldots, B_{K}$, respectively. Let

$$
\sum_{A_{i} \cap B_{j}=\varnothing} m_{1}\left(A_{i}\right) m_{2}\left(B_{j}\right)<1 .
$$

Then the function $m: 2^{\Theta} \rightarrow[0,1]$ defined by (4) is the composite basic probability assignment. Consider

$$
\begin{gathered}
m(A)= \begin{cases}0, & A=\varnothing \\
\frac{\sum_{A_{i} \cap B_{j}=A} m_{1}\left(A_{i}\right) m_{2}\left(B_{j}\right)}{1-K}, & A \neq \varnothing,\end{cases} \\
K=\sum_{A_{i} \cap B_{j}=\varnothing} m_{1}\left(A_{i}\right) m_{2}\left(B_{j}\right) .
\end{gathered}
$$

(2) The Composition of Multiple Belief Functions. Let $\mathrm{Bel}_{1}$, $\ldots, \mathrm{Bel}_{n}$ be the functions in the same recognition framework and $m_{1}, \ldots, m_{n}$ be the corresponding basic probability assignments. If $\mathrm{Bel}_{1} \oplus \cdots \oplus \mathrm{Bel}_{n}$ exists and the composite basic probability assignment function is remembered as $m$, then for all $A \subset \Theta, A \neq \varnothing, A_{1}, \ldots, A_{n} \subset \Theta$. The value of basic probability assignment can be calculated by (5)

$$
\begin{gathered}
m(A)=\frac{\sum_{\substack{A_{1}, \ldots, A_{n} \subset \Theta \\
A_{1} \cap \cdots A_{n}=A}} m_{1}\left(A_{1}\right) \cdots m_{n}\left(B_{n}\right)}{1-K}, \\
K=\sum_{\substack{A_{1}, \ldots . . A_{n} \subset \Theta \\
A_{1} \cap \cdots \cap A_{n}=\varnothing}} m_{1}\left(A_{1}\right) \cdots m_{n}\left(B_{n}\right) .
\end{gathered}
$$

(3) The Decision-Making Based on Basic Probability Assignment. Let for all $A_{1}, A_{2} \subset \Theta$

$$
\begin{gathered}
m\left(A_{1}\right)=\max \left\{m\left(A_{i}\right), A_{i} \subset \Theta\right\}, \\
m\left(A_{2}\right)=\max \left\{m\left(A_{i}\right), A_{i} \subset \Theta \text { and } A_{i} \neq A_{1}\right\}, \\
m\left(A_{1}\right)-m\left(A_{2}\right)>\varepsilon_{1}, \\
m(\Theta)<\varepsilon_{2}, \\
m\left(A_{1}\right)>m(\Theta) .
\end{gathered}
$$

If all the conditions of (6) are satisfied, then $A_{1}$ is the judgmental result, where $\varepsilon_{1}$ and $\varepsilon_{2}$ are preset thresholds. The difference between the maximal basic probability assignment and any other basic probability assignment should be larger than $\varepsilon_{1}$. The basic probability assignment of the judgment's uncertainty should be smaller than $\varepsilon_{2}$. In addition, the basic probability assignment of uncertainty should be smaller than that of the judgmental result. Therefore, the larger $\varepsilon_{1}$ and the smaller $\varepsilon_{2}$ is, the more accurate the judgmental result will be.

\subsection{Operational Risk Assessment Model Based on Rough Set} and D-S Evidence Theory. Combined with rough set theory and D-S evidence theory, this paper built an operational risk assessment model of distribution network equipment operational risk assessment model, and the detailed steps are as follows.

(1) Apply reduction function of rough set to the index reduction of distribution network equipment operational risk (the selection of original indexes depends on the specific equipment). After index reduction, one or multiple indexes may be left.

(2) For the reduction of multiple indexes, use the collection rule of D-S evidence theory to combine the reduced indexes and get the basic probability assignment of various index combination results.

(3) After the basic probability assignment of each reduction is obtained, there is no need to assess the operational risk of distribution network equipment by a single reduction. Use the collection rule of D$S$ evidence theory to combine the reductions and get the results of all the combinations. Then by adopting the decision-making method based on basic belief assignment and the combination results above, the operational risk level of distribution network can be evaluated.

\section{Numerical Example}

As one of the main equipment in distribution network, the operational risk of transformer is an important part of distribution network operational risk. So, the transformer is chosen to make an analysis of the numerical example in this paper. The basic data of transformer operation came from article [22], and 15 representative samples were chosen for this research. For each category of operational risk indexes, the risk level was represented by numbers $1-5$, and the sample data was shown in Table 1 . When a problem occurs inside the transformer, insulating oil will decompose major characteristic gases such as $\mathrm{H}_{2}, \mathrm{CH}_{4}, \mathrm{C}_{2} \mathrm{H}_{2}, \mathrm{C}_{2} \mathrm{H}_{4}$, and $\mathrm{C}_{2} \mathrm{H}_{6}$. The volume fraction of the characteristic gas is closely related to the operational risk level, but there is no clear mapping relation.

3.1. Attribute Reduction Based on Discernibility Matrix. The index reduction based on rough set theory is built on the basis of discrete data, so the continuous attributes should be discretized firstly. The discretization of continuous attribute is usually determined by the intervals given by experts' experience or the system's automatic division of the input data according to a certain principle. For the data in Table 1, the rules for data discretizing were established as shown in Table 2.

In order to facilitate the operation process, we use symbols $A, B, C, D, E, F, G, H$ to represent the operational risk of $\mathrm{C}_{2} \mathrm{H}_{2} / \mathrm{C}_{2} \mathrm{H}_{4}, \mathrm{C}_{2} \mathrm{H}_{4} / \mathrm{C}_{2} \mathrm{H}_{6}, \mathrm{C}_{2} \mathrm{H}_{6} / \mathrm{C}_{2} \mathrm{H}_{4}, \mathrm{CH}_{4} / \mathrm{C}_{2} \mathrm{H}_{4}$, $\mathrm{C}_{2} \mathrm{H}_{2} / \mathrm{CH}_{4}, \mathrm{C}_{2} \mathrm{H}_{2} / \mathrm{C}_{2} \mathrm{H}_{6}, \mathrm{H}_{2} /\left(\mathrm{H}_{2}+\right.$ hydrocarbon), and operational risk level, respectively, where $A, B, C, D, E, F, G$ are condition attributes and $\mathrm{H}$ is the decision attribute. Use the discretization rules in Table 2 to discretize the operational risk assessment data in Table 1 and merge the duplicate data, then build the discernibility matrix according to (1). The results are shown in Table 3. 
TABLE 1: Operational risk assessment data of a transformer in a certain working condition.

\begin{tabular}{|c|c|c|c|c|c|c|c|c|}
\hline ID & $\mathrm{C}_{2} \mathrm{H}_{2} / \mathrm{C}_{2} \mathrm{H}_{4}$ & $\mathrm{C}_{2} \mathrm{H}_{4} / \mathrm{C}_{2} \mathrm{H}_{6}$ & $\mathrm{C}_{2} \mathrm{H}_{6} / \mathrm{C}_{2} \mathrm{H}_{4}$ & $\mathrm{CH}_{4} / \mathrm{C}_{2} \mathrm{H}_{4}$ & $\mathrm{C}_{2} \mathrm{H}_{2} / \mathrm{CH}_{4}$ & $\mathrm{C}_{2} \mathrm{H}_{2} / \mathrm{C}_{2} \mathrm{H}_{6}$ & $\mathrm{H}_{2} /\left(\mathrm{H}_{2}+\right.$ hydrocarbon $)$ & Risk level \\
\hline 1 & 1.231 & 0.765 & 0.596 & 2.192 & 0.561 & 0.941 & 0.355 & 1 \\
\hline 2 & 0.055 & 6.455 & 1.100 & 0.141 & 0.390 & 0.355 & 0.065 & 1 \\
\hline 3 & 0.074 & 0.257 & 2.763 & 1.407 & 0.053 & 0.019 & 0.461 & 2 \\
\hline 4 & 0.000 & 0.588 & 0.642 & 2.650 & 0.000 & 0.000 & 0.837 & 2 \\
\hline 5 & 1.141 & 1.873 & 0.245 & 2.179 & 0.524 & 2.136 & 0.580 & 2 \\
\hline 6 & 0.348 & 12.760 & 0.183 & 0.428 & 0.813 & 4.444 & 0.269 & 3 \\
\hline 7 & 1.189 & 7.944 & 0.269 & 0.469 & 2.537 & 9.444 & 0.457 & 3 \\
\hline 8 & 1.455 & 14.000 & 0.103 & 0.695 & 2.093 & 0.364 & 0.204 & 3 \\
\hline 9 & 0.000 & 1.059 & 0.611 & 1.544 & 0.000 & 0.000 & 0.010 & 4 \\
\hline 10 & 0.007 & 2.545 & 0.266 & 1.476 & 0.005 & 0.018 & 0.332 & 4 \\
\hline 11 & 0.003 & 1.500 & 0.467 & 1.429 & 0.002 & 0.005 & 0.122 & 4 \\
\hline 12 & 0.017 & 18.218 & 0.146 & 0.375 & 0.045 & 0.309 & 0.159 & 5 \\
\hline 13 & 0.000 & 5.739 & 0.110 & 1.500 & 0.000 & 0.000 & 0.303 & 5 \\
\hline 14 & 0.029 & 11.429 & 0.124 & 0.708 & 0.041 & 0.333 & 0.201 & 5 \\
\hline 15 & 0.049 & 4.727 & 0.515 & 0.411 & 0.113 & 0.219 & 0.113 & 5 \\
\hline
\end{tabular}

TABLE 2: Discretization rules of the transformer operational risk assessment data.

\begin{tabular}{|c|c|c|c|c|c|c|}
\hline Item & Original data scope & Discretized data & Original data scope & Discretized data & Original data scope & Discretized data \\
\hline$A$ & $0.000 \sim 0.500$ & 0 & $0.501 \sim 1.000$ & 1 & $1.001 \sim 1.500$ & 2 \\
\hline$B$ & $0.000 \sim 5.000$ & 0 & $5.001 \sim 10.000$ & 1 & $10.001 \sim 20.000$ & 2 \\
\hline C & $0.000 \sim 0.500$ & 0 & $0.501 \sim 1.000$ & 1 & $1.001 \sim 3.000$ & 2 \\
\hline$D$ & $0.000 \sim 0.900$ & 0 & $0.901 \sim 1.800$ & 1 & $1.001 \sim 2.700$ & 2 \\
\hline E & $0.000 \sim 0.500$ & 0 & $0.501 \sim 1.500$ & 1 & $1.501 \sim 3.000$ & 2 \\
\hline$F$ & $0.000 \sim 0.500$ & 0 & $0.501 \sim 1.000$ & 1 & $1.001 \sim 10.000$ & 2 \\
\hline$G$ & $0.000 \sim 0.300$ & 0 & $0.301 \sim 0.600$ & 1 & $0.601 \sim 0.900$ & 2 \\
\hline
\end{tabular}

TABLE 3: Discernibility matrix of the transformer.

\begin{tabular}{lccccr}
\hline Order & 1 & 2 & 3 & 4 & 5 \\
\hline 1 & $\varnothing$ & & & & \\
2 & $A, C, D, E, F$ & $\varnothing$ & & & \\
3 & $A, B, C, D, F, G$ & $B, C, D, E, F, G$ & $\varnothing$ & & \\
4 & $A, D, E, F, G$ & $C, G$ & $B, C, D, E, F$ & $\varnothing$ & \\
5 & $A, B, C, D, E, F$ & $B, C$ & $B, D, E, F, G$ & $B, C, G$ & $\varnothing$ \\
\hline
\end{tabular}

According to (2), the discernibility function of the transformer's risk level is shown as

$$
\begin{aligned}
\Delta= & (A \vee C \vee D \vee E \vee F) \cdot(A \vee B \vee C \vee D \vee F \vee G) \\
& \cdot(A \vee D \vee E \vee F \vee G) \cdot(A \vee B \vee C \vee D \vee E \vee F) \\
& \cdot(B \vee C \vee D \vee E \vee F \vee G) \cdot(C \vee G) \cdot(B \vee C) \\
& \cdot(B \vee C \vee D \vee E \vee F) \cdot(B \vee D \vee E \vee F \vee G) \\
& \cdot(B \vee C \vee G)=C \vee D F .
\end{aligned}
$$

It can be concluded that there are two reductions, namely, $\{C\}$ and $\{D, F\}$.

3.2. Index Combination Based on D-S Evidence Theory. The two attribute reductions to assess the operational risk
TABLE 4: Basic probability assignment of risk status.

\begin{tabular}{lcccccc}
\hline & Class 1 & Class 2 & Class 3 & Class 4 & Class 5 & $\varnothing$ \\
\hline $\mathrm{C}_{2} \mathrm{H}_{6} / \mathrm{C}_{2} \mathrm{H}_{4}$ & 0.32 & 0.14 & 0.24 & 0 & 0.20 & 0.1 \\
$\mathrm{CH}_{4} / \mathrm{C}_{2} \mathrm{H}_{4}$ & 0.24 & 0.34 & 0.15 & 0 & 0.17 & 0.1 \\
$\mathrm{C}_{2} \mathrm{H}_{2} / \mathrm{CH}_{4}$ & 0.12 & 0.25 & 0.20 & 0 & 0.33 & 0.1 \\
\hline
\end{tabular}

status of the transformer are $\left\{\mathrm{C}_{2} \mathrm{H}_{6} / \mathrm{C}_{2} \mathrm{H}_{4}\right\}$ and $\left\{\mathrm{CH}_{4} /\right.$ $\left.\mathrm{C}_{2} \mathrm{H}_{4}, \mathrm{C}_{2} \mathrm{H}_{2} / \mathrm{CH}_{4}\right\}$. For a record of status information, if the results of operational risk status obtained from the assessment of the two attribute reductions, respectively, are consistent, then there is no need to conduct any auxiliary judgment; if the results of operational risk status are inconsistent, which one prevails? At this time, the result from the two reductions should be handled by the use of D-S combination rule, and the one with the largest confidence is the final risk status result. For example, if the evidence value of $\mathrm{C}_{2} \mathrm{H}_{6} / \mathrm{C}_{2} \mathrm{H}_{4}$ is 0.501 , the operational risk status of the transformer is 3,4 , or 5 , and we cannot simply judge it to be 3 . From the perspective of evidence theory, the confidences of the operational risk status belonging to 3,4 , or 5 are $1 / 3$, respectively. Therefore, we need to define the calculation method for the basic probability assignment of the index reduction and use the decision-making approach based on 
TABLE 5: Combination results of $\mathrm{CH}_{4} / \mathrm{C}_{2} \mathrm{H}_{4}$ and $\mathrm{C}_{2} \mathrm{H}_{2} / \mathrm{CH}_{4}$.

\begin{tabular}{lcccccc}
\hline & Class 1 & Class 2 & Class 3 & Class 4 & Class 5 & $\varnothing$ \\
\hline$\left\{\mathrm{CH}_{4} / \mathrm{C}_{2} \mathrm{H}_{4}, \mathrm{C}_{2} \mathrm{H}_{2} / \mathrm{CH}_{4}\right\}$ & 0.1083 & 0.6278 & 0.1093 & 0 & 0.1188 & 0.0358 \\
\hline
\end{tabular}

TABLE 6: Combination results of $\mathrm{C}_{2} \mathrm{H}_{6} / \mathrm{C}_{2} \mathrm{H}_{4}, \mathrm{CH}_{4} / \mathrm{C}_{2} \mathrm{H}_{4}$, and $\mathrm{C}_{2} \mathrm{H}_{2} / \mathrm{CH}_{4}$.

\begin{tabular}{lcccccr}
\hline & Class 1 & Class 2 & Class 3 & Class 4 & Class 5 & $\varnothing$ \\
\hline$\left\{\mathrm{C}_{2} \mathrm{H}_{6} / \mathrm{C}_{2} \mathrm{H}_{4}, \mathrm{CH}_{4} / \mathrm{C}_{2} \mathrm{H}_{4}, \mathrm{C}_{2} \mathrm{H}_{2} / \mathrm{CH}_{4}\right\}$ & 0.0234 & 0.9013 & 0.0323 & 0 & 0.04111 & 0.00189 \\
\hline
\end{tabular}

TABLE 7: Correspondence between gas ratio range and code using Rogers ratio method.

\begin{tabular}{|c|c|c|c|c|c|}
\hline \multirow{2}{*}{$\mathrm{CH}_{4} / \mathrm{H}_{2}$} & Ratio range & $>0.1,<1.0$ & $\geq 1.0,<3.0$ & $\geq 3.0$ & $\leq 0.1$ \\
\hline & Code & 0 & 1 & 2 & 3 \\
\hline \multirow{2}{*}{$\mathrm{C}_{2} \mathrm{H}_{6} / \mathrm{CH}_{4}$} & Ratio range & $<1.0$ & $\geq 1.0$ & & \\
\hline & Code & 0 & 1 & & \\
\hline \multirow{2}{*}{$\mathrm{C}_{2} \mathrm{H}_{4} / \mathrm{C}_{2} \mathrm{H}_{6}$} & Ratio range & $<1.0$ & $\geq 1.0,<3.0$ & $\geq 3.0$ & \\
\hline & Code & 0 & 1 & 2 & \\
\hline \multirow{2}{*}{$\mathrm{C}_{2} \mathrm{H}_{2} / \mathrm{C}_{2} \mathrm{H}_{4}$} & Ratio range & $<0.5$ & $\geq 0.5,<3.0$ & $\geq 3$ & \\
\hline & Code & 0 & 1 & 2 & \\
\hline
\end{tabular}

the basic probability assignment to assess the risk status after the index combination.

Let the operational risk status of the transformer be 5 categories, namely, Class 1, Class 2, Class 3, Class 4, and Class 5. Use $m(1), m(2), m(3), m(4)$, and $m(5)$ to represent the basic probability assignment of the risk status belonging to Class 1, Class 2, Class 3, Class 4, and Class 5, respectively. $m(\varnothing)$ represents the basic probability assignment of the uncertainty.

Assume the transformer's values of $\mathrm{C}_{2} \mathrm{H}_{6} / \mathrm{C}_{2} \mathrm{H}_{4}, \mathrm{CH}_{4} /$ $\mathrm{C}_{2} \mathrm{H}_{4}$, and $\mathrm{C}_{2} \mathrm{H}_{2} / \mathrm{CH}_{4}$ monitored at a certain time are $0.953,1.345$, and 0.452 , respectively; then the calculated basic probability assignments are shown in Table 4.

According to the combination rule of $\mathrm{D}$-S evidence theory, the combination results of $\mathrm{CH}_{4} / \mathrm{C}_{2} \mathrm{H}_{4}$ and $\mathrm{C}_{2} \mathrm{H}_{2} / \mathrm{CH}_{4}$ are calculated, as shown in Table 5.

Combine the combination results of $\mathrm{CH}_{4} / \mathrm{C}_{2} \mathrm{H}_{4}$ and $\mathrm{C}_{2} \mathrm{H}_{2} / \mathrm{CH}_{4}$ in Table 5 with the evidence of $\mathrm{C}_{2} \mathrm{H}_{6} / \mathrm{C}_{2} \mathrm{H}_{4}$ in Table 4; the results are shown in Table 6.

It can be obtained from the combination results in Table 4 that the basic probability of each evidence's uncertainty is greater than or equal to 0.1 when single evidence is used for the judgment. Through evidence combination, uncertainty dropped substantially from 0.1 to 0.00189 , and the basic probabilities of transformer's operational risk status are 0.0234 , $0.9014,0.323,0$, and 0.0411 for each class. Among them, the basic probability assignment of Class 2 is the largest. Let the thresholds be $\varepsilon_{1}=0.1$ and $\varepsilon_{2}=0.01$; then the final assessment result of the transformer's risk status obtained from the decision-making approach based on the basic probability assignment is Class 2, and the uncertainty of the assessment result is 0.00189 .

3.3. Result Discussion. As the gases produced by oil and solid insulation materials under different temperatures and discharge modes differ in type and volume, the ratios among gas volume can be used to judge the operational fault properties of a device. In general, Rogers ratio method is widely used to judge the operational status of a transformer (shown in Tables 7 and 8). For this method, we should monitor the ratios of each gas volume with another in the transformer and compare them with Rogers ratios; then the risk status of the transformer can be determined. However, the conditions of each transformer are different, so the type and volume of gases needed for detecting are also different. Furthermore, there is no direct relationship between the monitoring ratios among some gas volumes and the final assessment result; thus inoperative ratios should be eliminated to simplify the evaluation process. Choosing the key indexes of ratios among gas volume to monitor is the future development trend of transformer operational risk assessment.

As assumed above, $\mathrm{C}_{2} \mathrm{H}_{6} / \mathrm{C}_{2} \mathrm{H}_{4}=0.953, \mathrm{CH}_{4} / \mathrm{C}_{2} \mathrm{H}_{4}=$ 1.345 , and $\mathrm{C}_{2} \mathrm{H}_{2} / \mathrm{CH}_{4}=0.452$ of a transformer were monitored at a certain time. Using the traditional method to perform operational risk evaluation, these values were translated into Rogers ratios which were shown as $\mathrm{C}_{2} \mathrm{H}_{6} / \mathrm{CH}_{4}=0.709$, $\mathrm{C}_{2} \mathrm{H}_{4} / \mathrm{C}_{2} \mathrm{H}_{6}=1.049$, and $\mathrm{C}_{2} \mathrm{H}_{2} / \mathrm{C}_{2} \mathrm{H}_{4}=0.608$. Based on the correspondence in Table 7 and diagnosis results in Table 8, the ratio of $\mathrm{CH}_{4} / \mathrm{H}_{2}$ should be further monitored to obtain the accurate risk assessment result. If $0.1<\mathrm{CH}_{4} / \mathrm{H}_{2}<$ 1.0, then the operational risk status of this transformer is judged as arc discharge-perfoliate discharge; else, we cannot get the assessment result from the existing fault diagnosis using Rogers ratio method.

Using the method proposed in this paper, the key operational risk measurement indexes are $\left\{\mathrm{C}_{2} \mathrm{H}_{6} / \mathrm{C}_{2} \mathrm{H}_{4}, \mathrm{CH}_{4} /\right.$ $\left.\mathrm{C}_{2} \mathrm{H}_{4}, \mathrm{C}_{2} \mathrm{H}_{2} / \mathrm{CH}_{4}\right\}$, the ratio of $\mathrm{CH}_{4} / \mathrm{H}_{2}$ needs no detection, and the basic probabilities of transformer's operational risk status for 5 class is $\{0.0234,0.9014,0.323,0,0.0411\}$. According to the principle of maximum membership degree, the transformer's risk level is Class 2. Based on the correspondence between risk assessment level and operational status 
TABle 8: Fault diagnosis using Rogers ratio method.

\begin{tabular}{lcccc}
\hline $\mathrm{CH}_{4} / \mathrm{H}_{2}$ & $\mathrm{C}_{2} \mathrm{H}_{6} / \mathrm{CH}_{4}$ & $\mathrm{C}_{2} \mathrm{H}_{4} / \mathrm{C}_{2} \mathrm{H}_{6}$ & $\mathrm{C}_{2} \mathrm{H}_{2} / \mathrm{C}_{2} \mathrm{H}_{4}$ & Diagnosis \\
\hline 0 & 0 & 0 & 0 & Normal aging \\
3 & 0 & 0 & 0 & Partial discharge (corona) \\
$1 \sim 2$ & 0 & 0 & 0 & Overheating $\left(\leq 150^{\circ} \mathrm{C}\right)$ \\
$1 \sim 2$ & 1 & 0 & 0 & Overheating $\left(150^{\circ} \mathrm{C} \sim 200^{\circ} \mathrm{C}\right)$ \\
0 & 1 & 0 & 0 & Overheating $\left(200^{\circ} \mathrm{C} \sim 300^{\circ} \mathrm{C}\right)$ \\
0 & 0 & 1 & 0 & Metal superheating \\
1 & 0 & 1 & 0 & Circular current in coil \\
1 & 0 & 2 & 0 & Circular current in iron core and shell or joint overload \\
0 & 0 & 0 & 1 & Arc discharge-no perfoliate discharge \\
0 & 0 & $1 \sim 2$ & 1 & Arc discharge-perfoliate discharge \\
0 & 0 & 2 & 2 & Continuous discharge breakdowns \\
3 & 0 & 0 & $1 \sim 2$ & Partial discharge-corona (sign of creepage) \\
\hline
\end{tabular}

TABLE 9: Correspondence between operational risk level and status.

\begin{tabular}{lc}
\hline Risk level of the transformer & Corresponding status \\
\hline 1 & Normal \\
2 & Low-energy discharge \\
3 & High-energy discharge \\
4 & Low-temperature overheating \\
5 & High-temperature overheating \\
\hline
\end{tabular}

(shown in Table 9), the transformer is in a state of lowenergy discharge, which means there is a certain degree of operational risk and some measures should be taken. For the operational risk status of low-energy discharge, this paper proposed risk handling measures from three aspects: adopting insulating paper and cardboard with low dielectric constant to improve the field-intensity distribution, removing the paint film of the connection parts in the earthed metal, and controlling feeding channel of the insulation to avoid metal foreign bodies in the insulation parts.

As the corresponding relationships in Tables 8 and 9 are subject to different characteristics standards and the risk status descriptions are inconsistent, we got the different risk status judgments. But with the proposed method in this paper, we got a more certain assessment result with reduced risk indexes. As for the classification and description of fault diagnosis, much more research has to be done based on data mining technology, expert experience, and so on.

\section{Conclusion}

As the equipment of distribution network becomes more complex, compact, and automated, a small fault inside the equipment may lead to the operational risk of the distribution network or even the whole power system as a result of chain reaction. So it is of great theoretical and practical significance to evaluate the operational risk of the distribution network scientifically. Based on the study of rough set theory and D-S evidence theory, this paper proposed an operational risk assessment method of distribution network equipment.
Taking the transformer as an instance, and obtaining its' operational monitoring data, this paper used the reduction function of the rough set to reduce the operational risk indexes of the transformer. Then the D-S evidence theory was adopted to combine the optimized indexes and further improve the accuracy of transformer's risk assessment. With method comparasion and application discussion, results showed that the method proposed in this paper is not only able to get the risk assessment indexes of the distribution network equipment more exactly, but is also able to deal with the uncertainty of the evidence efficiently. It provides helpful thoughts for the quantitative risk assessment of distribution network equipment.

\section{Acknowledgments}

This study is funded by the National Natural Science Foundation of China (Grant no. 71071054; 71271084) and "the Fundamental Research Funds for the Central Universities". The authors appreciate the anonymous reviewers for their valuable comments, which were helpful in improving the paper.

\section{References}

[1] S. A. M. Javadian and M. R. Haghifam, Eds., "Analysis of protection system's risk in distribution networks with DG," International Journal of Electrical Power \& Energy Systems, vol. 44, no. 1, pp. 688-695, 2013.

[2] J. H. Yang, Z. H. Yang, and L. Jun, Eds., "Risk assessment research on power transformers based on risk probability for power transformer," Power System and Clean Energy, vol. 28, no. 3, pp. 044-049, 2012 (Chinese).

[3] Y. L. Dong, Y. J. Gu, and K. Yang, Eds., "Criticality analysis on equipment in power plant based on Monte Carlo simulation," Proceedings of the Chinese Society of Electrical Engineering, vol. 23, no. 8, pp. 201-205, 2003.

[4] K. Bai and R. H. Luo, "Study on risk assessment of transmission and distribution equipments," Electric Power, vol. 42, no. 10, pp. 048-051, 2009. 
[5] Z. H. Dai, Z. P. Wang, and Y. Jiao, Eds., "Dynamic reliability assessment of protection system based on dynamic fault tree and Monte Carlo simulation," Proceedings of the Chinese Society of Electrical Engineering, vol. 31, no. 19, pp. 105-113, 2011.

[6] Z. L. Yang, Research on special equipment risk management [Ph.D. thesis], Tianjin University, Tianjin, China, 2008.

[7] X. P. Yang, H. P. Nan, and J. Zhang, Eds., "Application of information fusion technology on fault diagnosis of hydropower generating unit," Journal of Hydroelectric Engineering, vol. 23, no. 6, pp. 111-115, 2004.

[8] X. L. Wang and H. Y. Dong, Eds., "State evaluation of secondary device in $750 \mathrm{kV}$ power grid based on information fusion," Proceedings of the Chinese Society of Universities, vol. 25, no. 1, pp. 040-046, 2013.

[9] D. Xiao and P. Sun, Eds., "Transformer risk assessment based on the neural network and genetic algorithm," Yunnan Electric Power, vol. 40, no. 5, pp. 020-024, 2012 (Chinese).

[10] Y. H. Feng and X. J. Liu, Eds., "Power transformer risk assessment and repair decision based on cloud model," Rural Electrification, vol. 12, pp. 041-042, 2012 (Chinese).

[11] Q. Yu and W. G. Li, Eds., "A risk assessment method of power transformer based on fuzzy analytic hierarchy process and neural network," Journal of Hunan University(Natural Sciences), vol. 39, no. 5, pp. 059-064, 2012.

[12] Y. Y. Wang, Y. Yuan, J. Li, L. Du, and J. Zhou, Eds., "Fuzzy risk assessment model of power transformer based on Borda number theory," High Voltage Engineering, vol. 34, no. 12, pp. 26682673, 2008.

[13] J. N. Mordeson, "Rough set theory applied to (fuzzy) ideal theory," Fuzzy Sets and Systems, vol. 121, no. 2, pp. 315-324, 2001.

[14] L. Y. Zhai, L. P. Khoo, and S. Fok, Eds., "Feature extraction using rough set theory and genetic algorithms-an application for the simplification of product quality evaluation," Computers and Industrial Engineering, vol. 43, no. 4, pp. 661-676, 2002.

[15] E. H. T. Francis and L. X. Shen, "Economic and financial prediction using rough sets model," European Journal of Operational Research, vol. 141, no. 3, pp. 641-659, 2002.

[16] E. H. T. Francis and L. X. Shen, "Fault diagnosis based on Rough Set Theory," Engineering Applications of Artificial Intelligence, vol. 16, no. 1, pp. 39-43, 2003.

[17] F. Witlox and H. Tindemans, Eds., "The application of rough sets analysis in activity-based modelling. Opportunities and constraints," Expert Systems with Applications, vol. 27, no. 4, pp. 585-592, 2004.

[18] J. B. Geng, W. Qiu, X. Kong, and H. Liu, Eds., “Technical condition evaluation for devices based on rough set theory and D-S evidence theory," Systems Engineering and Electronics, vol. 30, no. 1, pp. 112-115, 2008.

[19] T. Li and Q. Feng, Eds., "Threat assessment based on entropy weight grey incidence and D-S theory of evidence," Application Research of Computers, vol. 30, no. 2, pp. 380-382, 2013.

[20] X. F. Fan and M. J. Zuo, "Fault diagnosis of machines based on D-S evidence theory. Part 2: application of the improved D-S evidence theory in gearbox fault diagnosis," Pattern Recognition Letters, vol. 27, no. 5, pp. 377-385, 2006.

[21] K. Guo and W. Li, "Combination rule of D-S evidence theory based on the strategy of cross merging between evidences," Expert Systems with Applications, vol. 38, no. 10, pp. 1336013366, 2011.

[22] X. F. Qian, Application of rough set theory in the transformer fault diagnosis [M.S. thesis], Nanjing University of Science \& Technology, Jiangsu, China, 2005. 


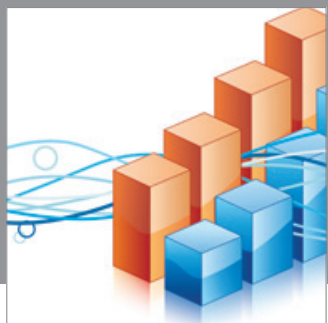

Advances in

Operations Research

mansans

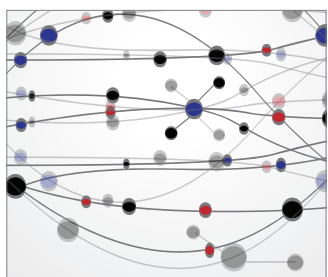

The Scientific World Journal
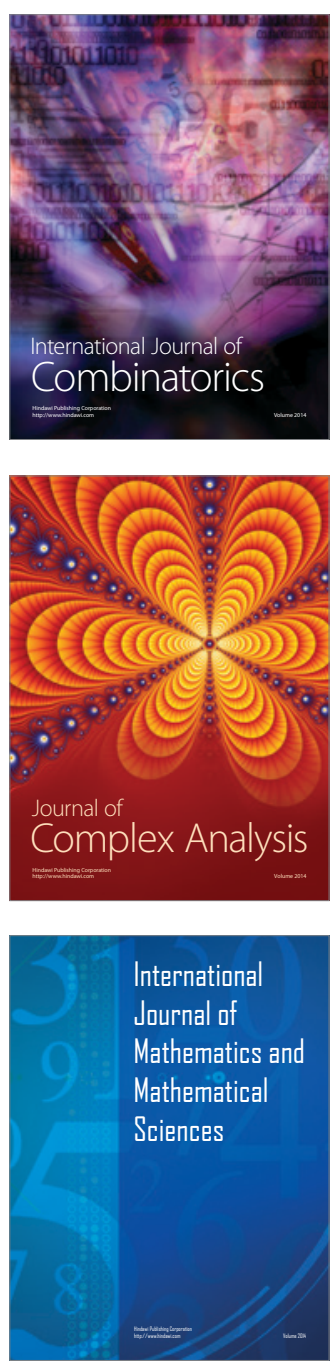
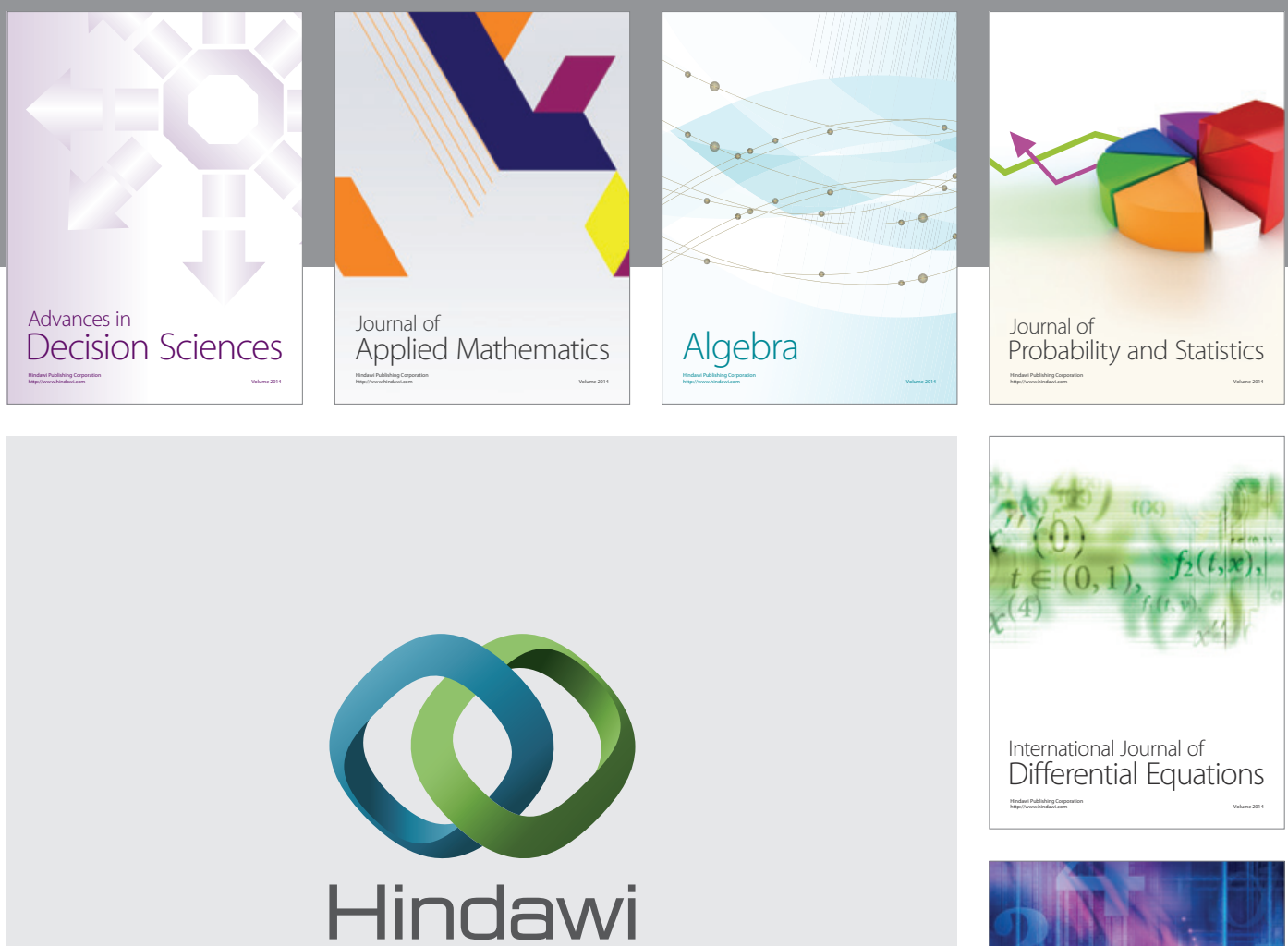

Submit your manuscripts at http://www.hindawi.com
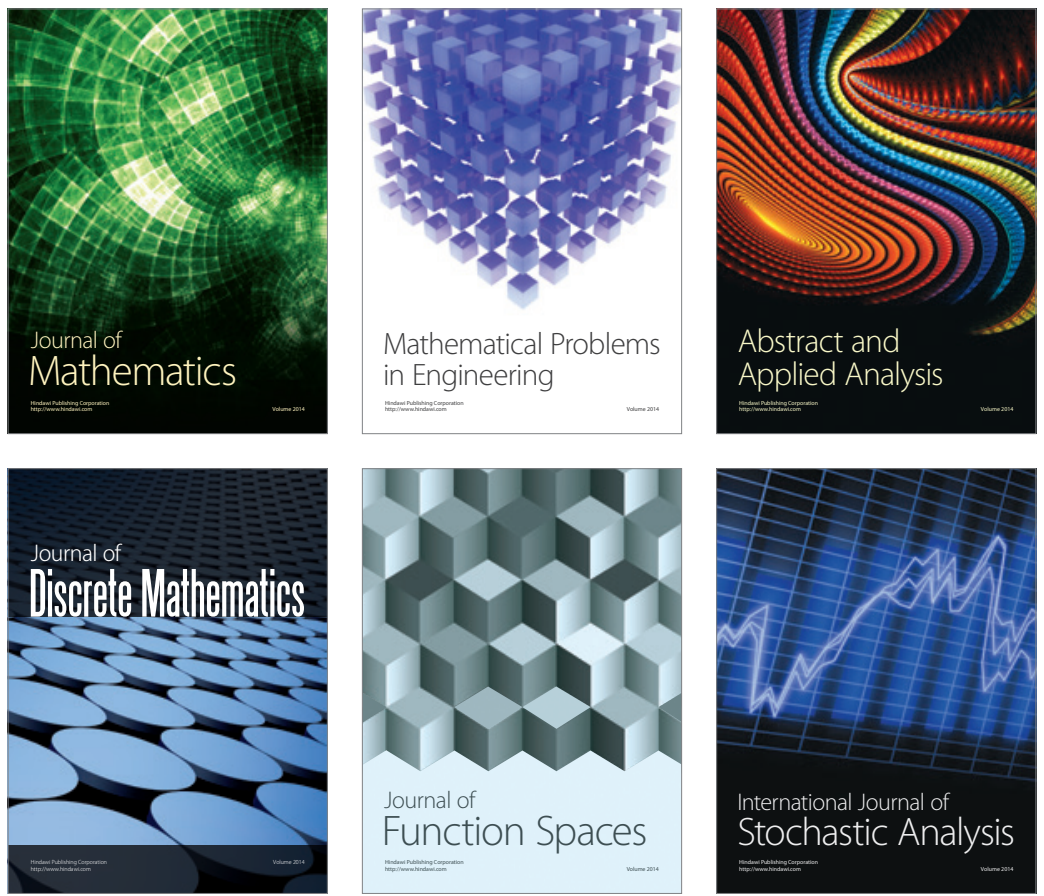

Journal of

Function Spaces

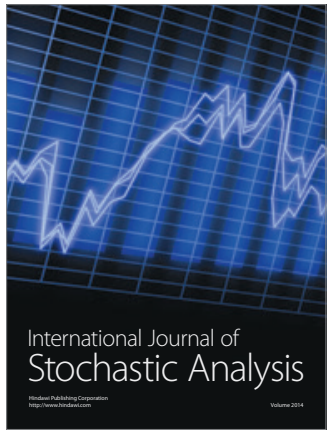

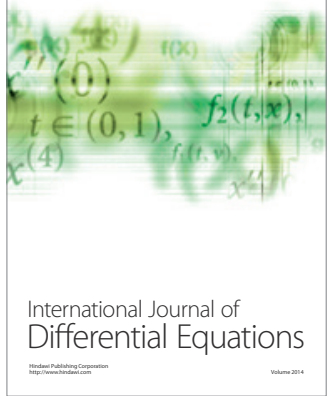
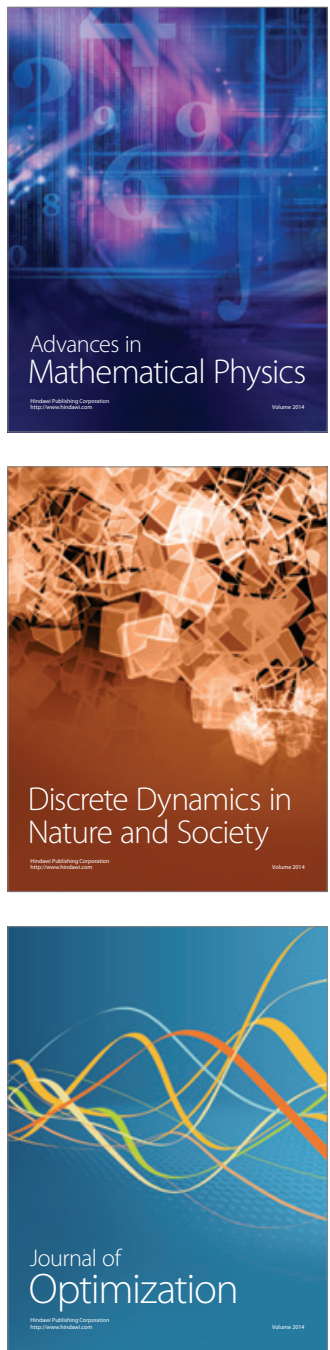